\title{
Editorial for the Special Issue
}

\author{
Hiroshi YAMA ${ }^{1)}$ and Ken I. MANKTELOW ${ }^{1)}$
}

${ }^{1)}$ Kobe College, Japan and University of Wolverhampton, U.K.

Research on human reasoning has been thought to have a special place in the field of thinking or problem solving. One of the reasons for this may be that many of the tasks used in reasoning studies have originated in logic or probability theory. People have mistakenly believed that research on human reasoning could be applied to just specific cases where people have to use logic or probability to make an inference. Furthermore, some students claim that such cases are less worthy of discussion than the usual kinds of problem solving because they are very artificial and thus are seldom seen in people's everyday lives. Therefore, this argument goes, it is not very worthwhile studying human reasoning, and the results gained from these studies cannot be directly applied to explanations of people's everyday thinking.

However, we do not agree with the claims. Logic was invented so that humans could think rationally. In other words, it is one of the products of a culture where people are adaptive if they think logically. Therefore, we like to take the view that logic and thinking have developed interactively, just as cultural psychologists take the view that culture and mind have been shaped interactively (Markus \& Kitayama, 1991).

We know that not all the contributors of this Special Issue completely agree with our view. But they strongly believe in the significance of reasoning research. Because reasoning tasks have well-defined logical or probabilistic structures, they are easy for psychologists to deal with. Hence the studies using such reasoning tasks have given rise to significant theories not only for reasoning itself but for all fields of cognition. Students have encountered many important debates inspired by these theories. For example, the debate between theorists who prefer rule-based accounts of reasoning (e.g. Braine \& O'Brien, 1998) and those who prefer mental models accounts (Johnson-Laird, 1983), the debate regarding the extent of abstractness of representation (Cheng \& Holyoak, 1985), and the debate between evolutionary psychologists (Cosmides, 1989) and dual process theorists (Over, 2003; Stanovich, 2004). The third of these, in particular, involves not only cognitive psychology but all the cognitive sciences.

Recently, in order to discuss the debates in the last decade, the first guest editor published a book on thinking, evolution, and culture (Yama, 2003), and the second guest editor published a book on reasoning and thinking (Manktelow, 1999) and edited a book on historical and theoretical currents in the psychology of reasoning (Manktelow \& Chung, 2004). They are all books reflecting recent trends in reasoning studies and thus

Correspondence: Professor Hiroshi Yama, Department of Human Sciences, Kobe College, Nishinomiya 662-8505, Japan (yama@mail.kobe-c.ac.jp) or Professor Ken I. Manktelow, School of Applied Sciences, University of Wolverhampton, Millennium City Building, Wulfruna Street, Wolverhampton WV1 1SB, UK (e-mail: k.i.manktelow@wlv.ac.uk). 
they concern the three debates. The key word that we commonly share is "rationality". Rationality has been one of the biggest problems in philosophy. It has recently been discussed in cognitive and evolutionary psychology how seemingly irrational problem solving can be rational from another view (Anderson, 1990; Evans \& Over, 1996; Manktelow \& Over, 1993). We are very happy to edit the Special Issue on Reasoning of Psychologia and contribute further to the development of debate on this issue.

Finally, we would like to express our gratitude not only to the contributors but to the reviewers who gave each contributor invaluable comments: Gary L. Brase (University of Missouri, Columbia), Mike Oaksford (University of Wales, Cardiff), and Tom Ormerod (University of Lancaster).

\section{REFERENCES}

Anderson, J. R. 1990. The adaptive character of thought. Hillsdale, NJ: Lawrence Erlbaum.

Braine, M. D. S., \& O’Brien, D. P. 1998. Mental logic. Mahwah, HJ: Lawrence Erlbaum.

Cosmides, L. 1989. The logic of social exchange: Has natural selection shaped how human reason? Studies with the Wason selection task. Cognition, 31, 187-276.

Evans, J. St. B. T., \& Over, D. E. 1996. Rationality and reasoning. Hove, UK: Psychology Press.

Johnson-Laird, P. N. 1983. Mental models. Cambridge: MA: Harvard University Press.

Manktelow, K. I. 1999. Reasoning and thinking. Hove, UK: Psychology Press.

Manktelow, K. I., \& Chung, M. C. 2004. Psychology of reasoning: Theoretical and historical perspectives. Hove, UK: Psychology Press.

Manktelow, K. I., \& Over, D. E. 1993. Rationality: Psychological and philosophical perspectives. London: Routledge.

Markus, H. R., \& Kitayama, S. 1991. Culture and the self: Implications for cognition, emotion, and motivation. Psychological Review, 98, 224-253.

Over, D. E. (Ed.). 2003. Evolution and the psychology of thinking. Hove, UK: Psychology Press.

Stanovich, K. E. 2004. The robot's rebellion: Finding meaning in the age of Darwin. Chicago: The University of Chicago Press.

Yama, H. 2003. Thinking, evolution, and culture. Kyoto: Nakanishiya-Shuppan. (In Japanese) 